\title{
Application of Mobile Technologies in Foreign Language Learners' Project Activity
}

\author{
https://doi.org/10.3991/ijim.v14i21.18471 \\ Rimma Ivanova ( $\left.{ }^{\bowtie}\right)$, Andrey Ivanov, Zhanna Nikonova \\ Linguistics University Nizhny Novgorod, Nizhny Novgorod, \\ Russian Federation \\ ivanovarimm6erambler.ru / holmann2009@yandex.ru
}

\begin{abstract}
The article analyzes the specific features of project work organization in English classes with blended mobile learning with the participation of students who previously haven't studied foreign languages or had school experience in learning other foreign languages - German or French. The relevance of the proposed work is caused by the application of the project method on the basis of mobile technologies that promotes the development of oral communication skills in the most effective way, taking into account the individual characteristics of the student and allows him in the future conducting a free conversation in a foreign language. The novelty of the methodology used lies in the complex application of systemic and integrative approaches using mobile technologies to the formation of oral skills in a foreign language. The hypothesis of the study that the application of the proposed teaching method contributes to a stable average for all students to improve the quality of knowledge throughout the entire period of study was fully confirmed. Student's participation in the project work and the use of mobile technology to share information and knowledge are an independent creative activity that ends with the creation of a fully communicative and linguistically correct speech message. Free speech in a foreign language based on student's own multimedia product is considered as a practical result of using an intensive method of teaching a foreign language from scratch.
\end{abstract}

Keywords - Intensive training, mobile learning, motivation, prepared and unprepared speech, project work

\section{Introduction}

An important feature of modern language training in higher education is its innovativeness, which implies the development of new language professional and cultural experience among students on the basis of creative and critical thinking, mobile and web-technologies, cognitive activity, problematic, dialogue-role modeling in the learning process. In modern conditions an intensive method of teaching foreign languages on base of mobile learning, which provides a significant improvement in the quality of education, compared to traditional methods [1-7].

Currently, the basis for organizing the process of teaching foreign languages should be a complex methodology that stimulates the project activities of students, the 
effectiveness of which largely depends on the mobile technology, used during the training. Correctly organized project activities contribute to the successful formation of the foreign language oral skills [8-11]. The project activity, which involves the wide use of accessible via mobile devices Internet resources, prepared by the students themselves, helps them to quickly move to a higher level of foreign language communication $[9,12]$. The organization of project learning activities is a complex task, as one of the objective conditions, ensuring its effectiveness, is the interactive nature of the used audiovisual mobile tools [13-15]. Subjective, but not less essential, the independence and motivation of first-year students, being the condition for successful project activity [16-21]. In this connection, the use mobile student generated content in the project work stimulates the independence of students and motivates them to situational and context-conditioned formatting of foreign speech, explicable in the mode of monological or dialogical statement [22-26].

The proposed study in the field of intensive mobile training of the first-year students in the higher educational institution includes the participation description and analysis of the students' involvement in the project activities, which in turn helps to form a reflexive approach for mastering the discipline "English language" through the activation of individual components:

- Axiological (motivation and values)

- Cognitive (development of intellectual and cognitive abilities)

- Vocational education (mastering the professional knowledge system)

- Technological (use of Internet technologies)

- Communicative (communicative skills)

- Regulatory (reflection and self-regulation as the basis of critical thinking) [27-31].

\section{Research Methodology}

The strategy for organizing the mobile project activity of students, described in this article, has authorial and online learning activity character and is based on theoretical and practical experience of the group of researchers in the field of project learning $[9,27]$ and in the field of mobile learning $[7,8,32]$.

The novelty of the proposed method is the integrated application of systemic and integrative approaches to the formation of the foreign language oral skills through the use of content creation and mobile access to it. The system approach provides simultaneous development of all types of speech activity using interactive forms of learning at different levels of communication between the teacher and student (formal / informal) through mobile devices. The integrative approach allows the teacher to organize project activities of students on the basis of their own methodological recommendations, and allows to create conditions that encourage learners to manifest their independence and a broader and more effective use of mobile web-based technologies in the course of work on the educational project [33].

The proposed method also takes into account the principle of variability, which is the individualization and differentiation of education, taking into account the characteristics of each student and the training group as a whole. The variability of the work 
organization on the project allows students to participate in the choice of the content for training and ways of its development, thereby increasing the level of their self-organization and motivation.

The study was conducted on a sample of 96 first-year students ( 52 of them women) of Nizhny Novgorod Linguistics University (Russia). The research was carried out over one semester with an exam in this discipline at the end. All participants belonged to students who either did not study a foreign language before, or studied another foreign language (German or French). All study participants agreed to participate in the study and received guarantees of the safety of their personal data. No personal data of the participants was used in the study, as only averages of their scores were calculated.

Since we are studying a program that has its own teaching methods and criteria for assessing individual modules, it was not possible to create a control group, since the rest of the student's study in other programs and the comparison of the learning effectiveness would be incorrect or should have been carried out on a special independent test. The development or use of such a test is one of the topics for future research. The quality of education was checked using oral tests on a 10-point scale. The assessment was carried out by 5 experienced teachers (more than 10 years of teaching English as a foreign language in Russian universities) according to a single set of requirements. For the purposes of the study, the average score was calculated for each of the parameters for each of the units and according to the results of the exam. This approach, as shown by the results of the study, is sufficient to identify relevant results. The hypothesis of the research is the assumption that as a result of the application of the described curriculum and the underlying teaching methodology, the results of oral practices of the majority of students will consistently improve. Based on the essence of the hypothesis, the use of the average values of the assessments for the group is adequate within the framework of the study, because the task is to uniformly improve the quality of the skills of the majority of students, which will be reflected by the dynamics of the average assessment.

The training process used the methodology detailed below. All types of assignments in the framework of projects for students involved the use of mobile devices and technologies available to students to create multimedia content within their projects: Graphics, sound recordings, video recordings, presentations, slides, etc. Mobile platforms were used to be able to instantly receive correction of pronunciation or completed assignments from the teacher, to discuss results with other students and to access study materials through cloud services. The main feature of the proposed method of mobile blended learning is the maximum free use of mobile tools familiar to students, which ensures the greatest ease and convenience in the process of project execution and knowledge exchange.

The innovative technique - students' project activity, which motivates them to situational and context-conditioned speaking in a foreign language both in the mode of monological or dialogical speech.

Project work is implemented in three phases. Each phase can be divided into stages.

1. Call phase: This stage first presupposes brainstorming, when the student thinks over the topic and prepares the project with multimedia support. 
2. Implementation phase: In this phase the student produces his monologue based on the project with the introduced technology before the audience and trains his speaking skills of the prepared monological speech. Then the learner answers questions of the group mates concerning the presented project, on the one hand, and the expert $\mathrm{s} /$ he is appointed from the other students' number - assesses both prepared and unprepared speech according to the criteria given before, on the other hand.

3. Free Discussion phase: This is a period of class time, when learners exchange their opinions, they can ask more questions to precise some items, to express their likes and dislikes, and after such a rather passionate and hot discussion they can come to the common conclusion, but there could sometimes be a case, while students fully disagree with the project and student's evaluation of the task. This is a really spontaneous discussion of the reviewed project and student's ability to "defend" the project.

Schematically, the phase structure of the successful implementation of project activities is as follows (see Fig. 1):

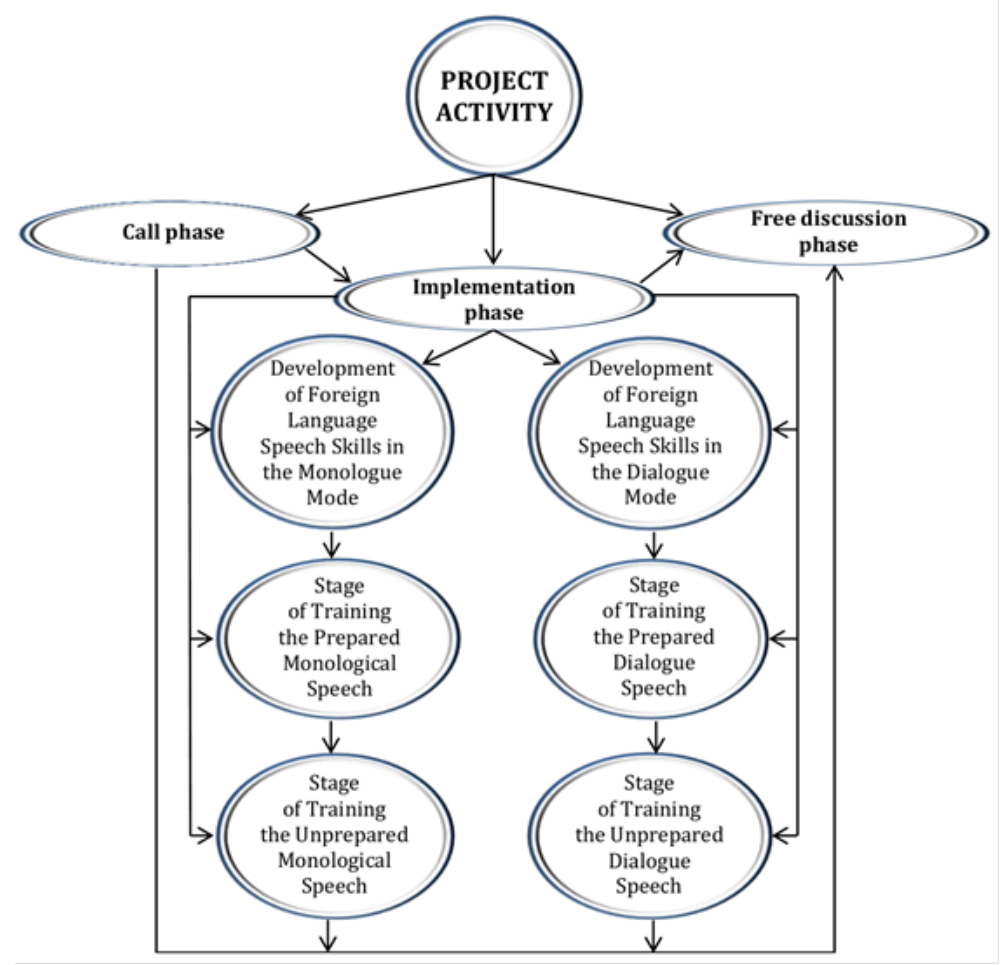

Fig. 1. The phase structure of students` project activity

A specific feature of the methodology used in teaching a foreign language from scratch in Nizhny Novgorod Linguistic University is that in a short time, through the involvement of students in broad educational project activities, using multimedia tools, 
it is possible to form stable communication skills of both prepared and unprepared foreign language speech, which allows most students to reach the B1+ level (Intermediate/ Intermediate + ). The main advantage of this method is the activation of all the students' personal reserves in the process of group training in a foreign language at a communicatively sufficient level in a given time frame.

This method is characterized by the involvement of students in educational project activities through situational and thematically organized communication, the use of role games, the use of computer and mobile technologies, the ability to search for necessary information on the Internet, the interrelated nature of learning all kinds of speech activity with the leading role of listening and speaking. As the author's experience shows, the project activity motivates the students not only to study the basics of the English language, but also contributes to the formation of an intelligent and competent person in the speech issue. The results of the training prove the effectiveness of the applied training method and confirm the positive dynamics that are revealed, while assessing the level of the skills' formation to learn a foreign spoken speech at all stages of studying English from scratch.

\section{$3 \quad$ Results}

As it was mentioned, Implementation phase (2) includes several stages.

\subsection{Development of foreign language speech skills in the monologue mode}

Stage of training the prepared monological speech: To start with the first topical unit, the teacher arranges the formation of skills and abilities of the prepared and unprepared monological speech. First of all, this practice should begin with topical vocabulary and grammar constructions, and then the teacher shows a project sample, while English learners answer teacher's questions about the model shown. In this way students' phonetics, grammar, vocabulary skills and ability to hold intelligent questionand-answer conversation on the basis of the studied material are activated. When all the recommendations, hints and prompts are given, the students prepare their own projects connected with the topic of the lesson.

It is worth mentioning that students present an oral 2-3-minute message based on a mini-presentation with a multimedia slide show support. They pronounce prepared texts based on the active vocabulary and known grammar constructions. Such an oral and media presentation on the thematic project allows students to activate their narrative skills, perfect lexical and grammatical material, learn to answer teacher's and groupmates' questions. The number of phrases is not less than 10-12 at the very beginning, and at an advanced step the number of sentences should be about 18-20, correctly formed in terms of language rules.

Stage of Training the Unprepared Monological Speech: At a more advanced stage, beginning from 4-5 units, depending on the general level of students' training, at the English lesson the expert from the number of students is appointed. She or he makes the detailed message containing the analysis of the listened presentation by certain 
criteria and estimates students' activity, giving them an assessment. This presentation is a kind of public unprepared speech, while an expert tries to analyze the project itself and makes the final conclusion about participation of each student in the project activity in general. For many students this oral speech is the first attempt to express their own point of view in English, and the teacher's objective is to assess a student-expert too. From the authors' experience, on the one hand, this type of group work with newcomers is the most complicated, because these students do not possess efficient skills for discussion and assessment in the mother language, but over some lessons most students like to be experts, and, moreover, some learners enjoy such an activity and offer themselves to broaden the types of work. For example, they bring their own videos, which are more amazing and include more challenging points for youngsters. They revise their own slideshows and even take photos and videos from their everyday life and propose these projects for free discussion. On the other hand, it should not be denied, that they have extremely little experience in speaking English, and to engage all the students into the project activity is a great issue for a teacher, therefore, the topics for speaking and further discussion must be clear, understandable and available for freshmen.

The assessment of student's project activity by the other student is considered as a probation period for the following stage in the group's project activity - to discuss the projects with no preliminary revision.

For this aim the teacher shows a topical project and inspires students to express their opinion. Using the studied phrases and word collocations from the unit, they practice their unprepared speech, mastering all the other skills - listening, vocabulary, grammar and speaking.

Newcomers must be very smart and responsible to arrange such a project activity, because the multimedia project itself must correspond to all the requirements, including the image and target of the slideshow.

Development of foreign language speech skills in the dialogue mode: Students should be able to talk using questions, exclamations, requests, orders, invitations, response remarks in the form of consent or refusal, clarification of information, in order to exchange views in connection with the heard or read content. The volume of replicas for each communication participant is not less than 6-8 replicas, correctly formed in terms of language rules.

Stage of training the prepared dialogue speech: Students prepare a multimedia project focusing on the topic in the video or mini-presentation in the dialogue mode. In the format of questioning / answering conversation they debate the happenings, demonstrating their aptitudes to critical thinking and realizing the current situation.

Such training work requires a preliminary preparation to the oral dialogical statement, and at the beginning it would better offer this mode to more successful students.

Stage of training the unprepared dialogue speech: A prepared multimedia project based on the proposed topic assists to arrange the teamwork activity in the group, and in 15-20 minutes the students have to speak and discuss the given task in the mode of unprepared foreign speech. These objectives for project activity are challenging enough, but very efficient for development of speaking skills.

During the classroom work, the first phase (evocation) of the project activity is envisaged, led by a teacher (teacher-led) or a student (students), if such a task is given 
(student-led). In this phase, there is an exchange of views, the establishment of the project content understanding, the definition of priority topics for discussion and division, if necessary, into mini-groups or pairs for further work. The second phase (realization of meaning) is an individual autonomous work of students, who are debating the target and objectives of the project. The third phase is a cross-talk in the conditions as close as possible to the real.

Free Discussion Phase (3) is the final one, on which students should demonstrate the advanced speaking skills in both modes of their learning activity - in the monologue and dialogue. It usually occurs in the last module, when students have a fairly wide range of skills and abilities, they can be engaged into free discussion after watching the project, presented in the form of the media product. The involvement of students into joint work is a core component of the project activity. Students' work is based on the following provisions:

- Students organize themselves in groups and sub-groups to view the project ("watching together entertains"), as joint watching creates a friendly atmosphere for further discussion.

- Students identify priority topics for discussion.

- Learners begin to interact better in situations where their opinion does not coincide with that of fellow students.

- In the course of communication, the students share situational roles of speakers, significantly affecting the nature of communication, among them:

- A leader, who wants to talk and control this project.

- A mediator, who monitors the overall course of the conversation, balancing the interests of different people.

- "A naughty child", violating any restrictions, acting with independent judgment;

- "A flexible person", ready to adapt to different situations, etc. [34].

- This kind of business role play requires much knowledge and many various skills, however, students prefer taking part in this role play, as it helps them to do the best in mastering their language skills.

Each unit begins with vocabulary and grammar and in the end of two weeks' learning process students receive the assignment in speaking. This activity includes exercises to describe any person, object or event. This task is given to students to be done at home and they prepare their presentations as a helpful tool to perform their speech by the help of information technologies. The students are sure to be elicited all the criteria to the project slideshow and speech relatively.

Having performed their speech and slide-show at lesson, students are asked followup questions, concerning the topic spoken in the whole and the presentation given in particular. This stage is called 'Unprepared Speech in Monologue'. The timescale is no more than 3-4 minutes, but some students, who are keen on the topic discussed, prefer asking a plenty of interrogatives. Some presentations are so exciting, so they need more time for dispute that contributes to development of speaking skills in discussion mode.

Then the unit finishes with the students' speaking in pairs or small groups (when the number of students is uneven, they are united in polylogue of 3 persons). From the very beginning they are engaged into participating in short dialogues without any 
preparation, using vocabulary studied and grammar known. Then they develop their dialogue skills, widening the number of topics and adding more and more words and set collocations to improve their score at lesson. This kind of lesson activity is sure to be one of the most attractive and adventurous for students. The authors' experience witnesses, learners enjoy this speaking activity very much.

The table shows that students' progress in the speech activities 'Monological Prepared Speech' and 'Dialogical Prepared Speech' is much better than 'Unprepared Speech in Monologue and Dialogue'. The grade for the 'Dialogical Prepared Speech' is 2 points higher than 'Monological Prepared Speech'. This difference can be elicited by the fact, that students enjoy speaking in a small group, where they are certain to find any assistance from their speech partner, and even if they forget some words or phrases they could be helped by the groupmate.

To summarize the mentioned above, the following ways of involving students in collaborative work prove the following:

1. Students initially perform a multimedia project (individually or jointly). As a result of work, first, they prepare a slide show or video, which available online via mobile devices and serves as a support for the creation of an oral report.

2. Students present their oral reports, which involve other students into the cross-talk.

3. As a result of the comprehensively studied topic, students prepare a project for targeted discussion in the format of free discussion.

4. Students produce an oral report in which they characterize the project prepared by another student and expose the assessment.

Experience proves that the assessment of an expert student often turns into the subject of discussion in the group, as students do not always agree with the assessment made by the expert. Students expend topics, discussing the advantages and disadvantages of students' participation in project activities in general, as well as give their recommendations to increase or decrease the expert assessment.

The strategy of the project organization work, aimed at solving the communicative task, is implemented in the conditions of the modular system of education in the higher education institution and involves detailed planning of the assignment stages with the indication of terms and resources, as well as the integration of various interactive technologies (Moodle, flashcards, web-quests, web-sites, slide-shows, video-presentations, etc.).

Involvement of students in the project activity allows, thus, to consolidate and develop the skills of independent work, while the use of mobile and multimedia technologies provides unlimited possibilities for organizing independent project activities, the purpose of which is to achieve the highest level of the formation of oral foreign language skills in a relatively short time.

For the purposes of the study, it is especially important that the standard deviation within the sample in the aggregate of estimates for one type of items in one model never exceeded 0.72 . This indicates a significant uniformity in the impact of the curriculum and a low variation in ratings across the entire experimental group. It also indicates the relevance of all the average estimates presented in Fig. 2, since almost all of these estimates lie outside the range of possible statistical deviations. 


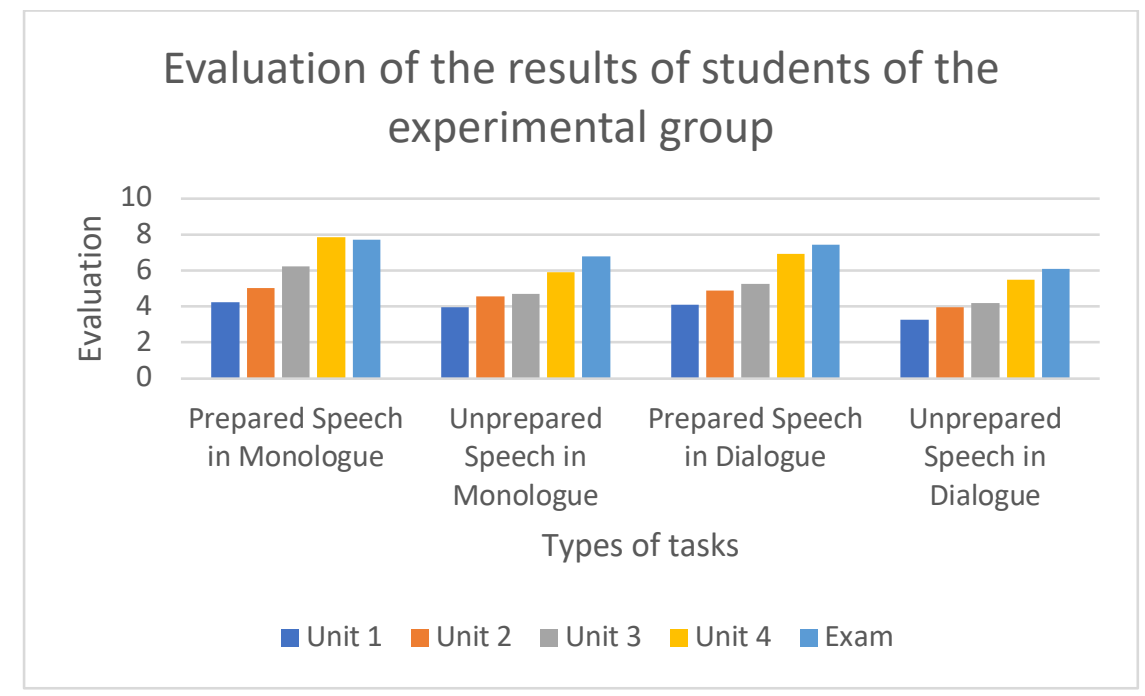

Fig. 2. Evaluation of the result of the experimental group.

Fig. 2 shows that in each of the types of assignments, there is a relevant increase in the average grade of students from unit to unit, and in all cases, except for "Prepared Speech in Monologue", the results obtained on the exam are higher than the marks for the previous units. In this case, the difference between the results of the exam and the last unit lies within the statistical error.

Thus, the success of the entire group, on average, evenly increases throughout the training with peak results after preparation for the exam, and we can say that the research hypothesis is fully confirmed.

The experience of using this teaching methodology also makes it possible to formulate a number of recommendations for teaching students to speak foreign language skills from scratch in a short time. Recommendations are presented in a separate section of this study.

\section{Discussion}

One of the most important factors, contributing to the study of the English language in conditions of intensive training, is the creation of an innovative model, using computer technologies, serving the basis for the formation and development of communicative skills for both prepared and unprepared oral speech in the mode of monologue and dialogue in the context of everyday communication. The introduction of knowledge-based technologies into the educational process promotes the development of competencies in various fields of human knowledge, including the formation and improvement of skills and abilities for foreign language speaking [18,19].

The project activity, in the course of which such features, peculiar for living speech, imagined by the students, as spontaneity, unexpectedness and novelty, appear to be an extremely productive way for organizing the independent work of students [35]. The 
communicative activity of students, participating in the project work, using innovative Internet technologies, is wholly aimed at achieving the required level of the foreign language communication skills.

The process of forming foreign communicative skills should be based on the principle of progressive movement from simple to complex, since "not easy, but accessible material is more interesting; an increased difficulty leads to uncertainty of students in their abilities and indifference to the subject" [16]. Therefore, the common feature for all types of classes with elements of the project method, based on information technology, is the project activity, that allows teachers to set communicative tasks at each specific stage of studying with a given level of complexity, motivating students not only to generate monological and dialogical statements, but to make a system analysis of linguistic facts. This training strategy has been used by authors for a number of years and has proved to be highly effective in preparing freshmen students entering the university on the basis of United State Exam results in German, French, Spanish.

It should be noted, that many published works that cover various aspects of higher education in foreign languages, mainly focus on teaching students who already have school experience in studying the English language course [2,5,24]. Scientific research on the use of Internet technologies in teaching foreign languages, as a rule, focuses on the results' analysis of their long-term use throughout the course of language studying $[7,20,36]$ and do not take into account the specifics of using ICT in conditions when the learning process is limited by a shortened time frame and is characterized by the setting of specific learning tasks.

The difference between the proposed strategy and the widely used one is in the training of students in a short time and the widespread use of widely available mobile services to continually improve students' skills. The researchers note that in reality, there is practically no confirmed research data on the level of effectiveness in teaching English as a foreign language for numerous specialized platforms or mobile applications. At the same time, there is a lot of evidence of increasing the effectiveness of learning when using blended or mobile distance learning with the widespread involvement of mobile devices and their capabilities [14,37]. By involving students in a diverse and thematically broad educational mobile project activity, using multimedia tools, it is possible to form stable communication skills of both prepared and unprepared foreign language speech without support on language knowledge and speech skills, received in the course of schooling, which allows the majority of students to reach the level of B1+ (Intermediate + ) in one year. The main advantage of the applied method is the activation of all the student's personal qualities, which, first of all, include its readiness for independent language activity, the ability to self-organize, the desire to solve communicative tasks of increasing complexity, both individually and in group, learning communication in a foreign language on communicatively sufficient level in a rigid time frame.

\section{Conclusion}

A study with the participation of 96 students from Nizhny Novgorod Linguistics University (Russia) using a new methodology for preparing for speaking skills in 
English with the wide use of mobile devices to constantly improve their skills has demonstrated a stable improvement in the quality of skills throughout the training. An objective assessment of this strategy can be considered successful in the majority of students passing the internal English exam in the first year, the results of which reflect the real achievements of students in the past academic period.

Participation in the project work is an independent creative activity that ends with the creation of a fully communicative and linguistically correct speech message. Throughout the course, mobile devices and access to web services were used for many types of learning activities and for contacting teachers, fixing mistakes on the go and working out communication skills with other students. Free speech in a foreign language based on your own multimedia product is considered as a practical result of using an intensive method of teaching a foreign language from scratch, aimed at developing beginners to get the English language communicative skills in the format of a prepared monologue and dialogue, as well as listening. In the future, such project of mobile, online and offline activities helps to form and develop students' skills of unprepared oral speech, as students are invited to discuss the project in a discussion mode and freely express their point of view of what they saw or heard.

The author's experience with all evidence shows that the proposed innovative learning model on the basis of the project provides students with a unique opportunity to master the language skills, including all aspects of language use: Phonetics, grammar, vocabulary. Teaching to students the phonetic, grammatical and lexical aspects of the foreign language, acquaintance with the specifics of word formation and word compatibility, active mastering of the most common vocabulary and phraseology does not take place in the form of memorizing a set of rules and exceptions, but in the process of working on coherent, finished in a semantic sense speech works.

\section{$6 \quad$ Recommendation}

It seems that the process of forming communicative skills corresponding to the level of "B1+" of the first-year students with a "0" level, meeting all the criteria of the European language portfolio, applied to this level, will be effective if the following conditions are realized during training:

- The active role of the teacher in the implementation of mobile project activities at the initial stage, using a wide inventory of information and communication technologies.

- The relevance and richness of the educational material online by mobile devices.

- Fascination of pedagogical actions.

- Cooperation of the teacher with students in the educational process at any time thanks to mobile contacts.

- Involvement of each student in the work.

- Encouraging in any form the personal success of students.

- Creation of a friendly psychological climate during the studying. 
- Selection of the most appropriate and economically linguistic ways of performing the task at each stage of studying.

- Autonomation of students' project activities.

- Application of various interactive forms with students in the course of studying (individual, pair, group) including using mobile communications.

- Maintaining constant feedback between the students, on the one hand, and the teacher and other students, on the other.

- Systematic control over the results of project activities.

- Making expert judgments based on reasoned opinion.

\section{$7 \quad$ References}

[1] Kendjayeva, Z. A. (2019). Teaching Foreign Languages Intensively. In Innovative Potential for the Development of Science in the Modern World: Technologies, Innovations, Achievements. Collection of articles based on the materials of the international scientific and practical conference. pp. 259-264.

[2] Shavkatova, R.F. (2019). Methods of using information technology in teaching foreign languages. Academy, 3(42): 1-10.

[3] Petrenko, M.A., Chopsieva, G.M. (2015). Innovative methods of teaching a foreign language. World of Science and Innovation, 6(2): 55-61.

[4] Mehdiyev, E. (2020). Opinions of EFL students regarding autonomous learning in language teaching. Dil ve Dilbilimi Çalışmaları Dergisi, 16(2): 521-536. https://doi.org/10.17263/j1 1s.759241

[5] Raju, N., Joshith, V.P. (2018). Krashen's Theory of Second Language Acquisition: A Practical Approach for English Language Classrooms. International Journal of Innovative Knowledge Concepts, 6(12): 179-184.

[6] Nassaji, H., Kartchava, E. (2017). Corrective feedback in second language teaching and learning: Research, theory, applications, implications. Vol. 66. Taylor \& Francis. https://doi .org/10.4324/9781315621432-1

[7] Qureshi, M.I., Khan, N., Gillani, S.M.A.H., Raza, H. (2020). A Systematic Review of Past Decade of Mobile Learning: What we Learned and Where to Go. International Journal of Interactive Mobile Technologies, 14(06): 67-81. https://doi.org/10.3991/ijim.v14i06.13479

[8] Liu, Z. Y., Spitsyna, N., Zubanova, S., \& Vekilova, A. (2020). Using Internet Resources for Remote Language Learning. International Journal of Emerging Technologies in Learning (iJET), 15(13): 22-33. https://doi.org/10.3991/ijet.v15i13.14653

[9] Cherkasov A.A., Bratanovskii S.N., Koroleva L.A., Zimovets L.G. (2019). Development of School Education in the Vologda Governorate (1725-1917). Part 1. European Journal of Contemporary Education, 8(1): 208-214. https://doi.org/10.13187/ejced.2019.1.208

[10] Zubkova, M.A., Fominykh, N.Iu., Baranova, E.N., Abbasova, L.Il., Pirozhkova, A.O., Bubenchikova, A.V., Maigeldieva, Sh.M. (2019). Approaches to the future engineer's foreign communicative culture formation. Humanities \& Social Sciences Reviews, 7(4): 781-786. https://doi.org/10.18510/hssr.2019.74101

[11] Hutchinson, T., Rézmüves, Z. (2019). Project 3: Teacher's Book with Online Practice. Oxford University Press.

[12] Kaminska, O., Stezhko, Y., Gliebova, L. (2019). Psycholinguistics of Virtual Communication in the Context of the Dependence on Social Networks. Psycholinguistics, 25(1): 147164. https://doi.org/10.31470/2309-1797-2019-25-1-147-164 
[13] Baptista, M., Martins, I., Conceição, T., Reis, P. (2019). Multiple representations in the development of students' cognitive structures about the saponification reaction. Chemistry Education Research and Practice, 20(4): 760-771. https://doi.org/10.1039/c9rp00018f

[14] Jamaldeen, F., Hewagamage, P., Ekanayaka, Y. (2018). Design guidelines for creating mobile language learning applications. International Journal of Interactive Mobile Technologies, 12(3): 52-74. https://doi.org/10.3991/ijim.v12i3.8153

[15] Dudley, J.J., Kristensson, P.O. (2018). A review of user interface design for interactive machine learning. ACM Transactions on Interactive Intelligent Systems, 8(2): 1-37. https:// doi.org/10.1145/3185517

[16] Biwer, F., oude Egbrink, M.G., Aalten, P., de Bruin, A. B. (2020). Fostering Effective Learning Strategies in Higher Education-A Mixed-Methods Study. Journal of Applied Research in Memory and Cognition, 9(2): 186-203. https://doi.org/10.1016/j.jarmac.2020.03.004

[17] Ball, B. (2019). Playing Games, Following Rules, and Linguistic Activity. Philosophical Insights into Pragmatics, 79, 127-142. https://doi.org/10.1515/9783110628937-007

[18] Yilmaz, Y., Granena, G. (2016). The role of cognitive aptitudes for explicit language learning in the relative effects of explicit and implicit feedback. Bilingualism, 19(1): 147-161. https://doi.org/10.1017/s136672891400090x

[19] Zhao, Q., Harper, F.M., Adomavicius, G., Konstan, J.A. (2018). Explicit or implicit feedback? Engagement or satisfaction? A field experiment on machine-learning-based recommender systems. In Proceedings of the 33rd Annual ACM Symposium on Applied Computing. pp. 1331-1340. https://doi.org/10.1145/3167132.3167275

[20] Lightbown, P.M., Spada, N. (2013). How languages are learned. 4th ed. Oxford Handbooks for Language Teachers. Oxford university press. https://doi.org/10.3138/cmlr.52.2.340

[21] Xu, J., Fan, Y., Xu, Q. (2019). EFL learners' corrective feedback decision-making in taskbased peer interaction. Language Awareness, 28(4): 329-347. https://doi.org/10. $\underline{1080 / 09658416.2019 .1668003}$

[22] Zhabo, N., Avdonina, M., Krivosheeva, E., Likhacheva, I., Meer, T. (2017). Modern methods of teaching foreign languages for specific purposes. In Conference proceedings. ICT for language learning. libreriauniversitaria. it Edizioni. pp. 288.

[23] Tareva, E.G., Shchepilova, A.V., Tarev, B.V. (2017). Intercultural content of a foreign language textbooks: concept, texts, practices. XLinguae Journal, 10(3): 246-255. https://doi.org $\underline{10.18355 / \mathrm{xl} .2017 .10 .03 .20}$

[24] Rubtsova, A., Almazova, N. (2019). Productive model of foreign languages learning: Realities and prospects. In International Conference Communicative Strategies of Information Society (CSIS 2018). Atlantis Press. https://doi.org/10.2991/csis-18.2019.65

[25] Klimova, B. (2018). Mobile phones and/or smartphones and their apps for teaching English as a foreign language. Education and Information Technologies, 23(3): 1091-1099. https:// doi.org/10.1007/s10639-017-9655-5

[26] Kuanysheva, B. T., Aubakirova, R. Z., Pigovayeva, N. I., \& Fominykh, N. I. (2019). Technologization of the Pedagogical Process as a Teacher Self-Improvement Factor. Journal of Social Studies Education Research, 10(3): 404-433.

[27] Wertheimer, M. (2020). Productive Thinking (1945). In Max Wertheimer Productive Thinking. Birkhäuser, Cham, pp. 25-257. https://doi.org/10.1007/978-3-030-36063-4_2

[28] Nold, H. (2017). Using Critical Thinking Teaching Methods to Increase Student Success: An Action Research Project. International Journal of teaching and learning in Higher Education, 29(1): 17-32.

[29] De Bono, E. (2017). Simplicity. Penguin UK.

[30] Lakoff, R.T. (2017). Context counts: Papers on language, gender, and power. Oxford University Press. 
[31] Goleman, D., Boyatzis, R. (2017). Emotional intelligence has 12 elements. Which do you need to work on. Harvard Business Review, 84(2): 1-5.

[32] Luzón, M.J. (2017). Connecting genres and languages in online scholarly communication: An analysis of research group blogs. Written communication, 34(4): 441-471. https://doi. org/10.1177/0741088317726298

[33] Ivanova, R.A., Ivanov, A.V., Lyashenko, M.S. (2017). A New Training Workshop for Students' IELTS Exam Mastering. Journal of Language \& Education, 3(2): 45-57. https://do i.org/10.17323/2411-7390-2017-3-2-45-54

[34] Azhmuhamedov, I., Azhmuhamedov, A.B.I., Machueva, D.A. (2016). Modeling of communication process in social environment. Journal of Theoretical \& Applied Information Technology, 85(2): 146-154.

[35] Granena, G., Yilmaz, Y. (2019). Corrective feedback and the role of implicit sequence-learning ability in 12 online performance. Language Learning, 69: 127-156. https://doi.org/10. 1111/lang.12319

[36] Markova, T., Glazkova, I., Zaborova, E. (2017). Quality issues of online distance learning. Procedia-Social and Behavioral Sciences, 237: 685-691. https://doi.org/10.1016/j.sbspro.20 $\underline{17.02 .043}$

[37] Zidoun, Y., Dehbi, R., Talea, M., El Arroum, F.Z. (2019). Designing a Theoretical Integration Framework for Mobile Learning. International Journal of Interactive Mobile Technologies, 13(12): 152-170. https://doi.org/10.3991/ijim.v13i12.10841

\section{Authors}

Ivanova Rimma Anvarovna is a PhD, Associate Professor of the Institute of Distance Learning, Linguistics University Nizhny Novgorod, Nizhny Novgorod, Russian Federation. Email: ivanovarimm6@rambler.ru /_holzmann2009@yandex.ru

Ivanov Andrey Vladimirovich is a $\mathrm{PhD}$ (Advanced Doctorate), Professor of the Department of German, Linguistics University Nizhny Novgorod, Nizhny Novgorod, Russian Federation.

Nikonova Zhanna Viktorovna is a $\mathrm{PhD}$ (Advanced Doctorate), Rector of Linguistics University Nizhny Novgorod, Nizhny Novgorod, Russian Federation.

Article submitted 2020-09-12. Resubmitted 2020-10-26. Final acceptance 2020-10-27. Final version published as submitted by the authors. 